\title{
Circuit Performance DEgRadation of SAMPlE-AND-Hold AmPlifier DUE TO GATE-OXIDE OVERSTRESS IN A 130-NM CMOS PROCESS
}

\author{
Jung-Sheng Chen and Ming-Dou Ker \\ Nanoelectronics and Gigascale Systems Laboratory \\ Institute of Electronics, National Chiao-Tung University, Hsinchu, Taiwan
}

\begin{abstract}
The effect of gate-oxide reliability on MOS switch in the bootstrapped circuit is investigated with the sample-and-hold amplifier in a 130-nm CMOS process. After overstress on the MOS switch of sample-and-hold amplifier, the circuit performances in the frequency domain are measured to verify the impact of gate-oxide reliability on circuit performance.
\end{abstract}

\section{INTRODUCTION}

The sample-and-hold amplifier (SHA) is an important building block in analog integrated circuits, such as analog-to-digital data converter (ADC). The high-speed and high-resolution analog-todigital data converter needs a high-performance sample-and-hold amplifier. The low-supply voltage will degrade the performance of the sample-and-hold amplifier due to the nonlinear effect of the MOSFET switch such as body effect, turn-on resistance variation, charge injection, and clock feedthrough. The bootstrapped technique provided a constant voltage between the gate and source terminals of the MOS switch is usually used to improve the performances of sample-and-hold amplifier under the low-supply voltage operation. However, the bootstrapped technique induces the gate-oxide overstress on MOS switch [1-4] to degrade the lifetime of the switch device. Therefore, the gate-oxide reliability on MOS switch in the sample-and-hold amplifier with the bootstrapped technique is a very important reliability issue in analog circuits. The thick-oxide MOSFET device [3] and the suitable device size of the bootstrapped switch circuit [1] can be used to avoid the gate-oxide overstress on the switch device. However, the impact of gate-oxide reliability on MOS switch in the sample-and-hold amplifier is still not investigated

In this work, the impact of gate-oxide reliability on MOS switch in the sample-and-hold amplifier circuit is investigated in a $130-\mathrm{nm}$ CMOS process. The frequency-domain performances of the sampleand-hold amplifier are measured after the gate-oxide overstress on MOS switch device.

\section{SAMPLE-AND-HOLD AMPLIFIER WITH BOOTSTRAPPED TECHNIQUE}

The conceptual schematic of the bootstrapped technique for sample-and-hold amplifier is shown in Fig. 1(a). The basic schematic includes the signal MOS switch $\mathrm{M}_{\mathrm{S}}$, five ideal switches $\mathrm{S}_{1}-\mathrm{S}_{5}$, and a capacitance $\mathrm{C}_{\mathrm{b}}$. The $\mathrm{CLK}_{1}$ and $\mathrm{CLK}_{2}$ clock signals are the out-ofphase signals. When $\mathrm{CLK}_{1}$ is low and $\mathrm{CLK}_{2}$ is high, the $\mathrm{S}_{3}$ and $\mathrm{S}_{4}$ switches charge the capacitance $C_{b}$ to the supply voltage $V_{D D}$, and the $\mathrm{S}_{5}$ switch is used to turn off the switch $\mathrm{M}_{\mathrm{S}}$. When $\mathrm{CLK}_{1}$ is high and $\mathrm{CLK}_{2}$ is low, the $\mathrm{S}_{1}$ and $\mathrm{S}_{2}$ switches change the capacitance $\mathrm{C}_{\mathrm{b}}$ in series with the input signal $V_{I N}$ and connect to the gate of switch $M_{S}$, such that the gate-to-source voltage across the switch $\mathrm{M}_{\mathrm{S}}$ is equal to the supply voltage $V_{D D}$. The gate voltage on the switch device $M_{S}$ will be charged to $V_{I N}+V_{D D}$, which is larger than the supply voltage. The detailed circuit implementation is shown in Fig. 1(b) [1]. The $M_{1}$, $\mathrm{M}_{2}, \mathrm{M}_{3}, \mathrm{M}_{4}$ and $\mathrm{M}_{5}$ correspond to the five ideal switches $\mathrm{S}_{1}-\mathrm{S}_{5}$ shown in Fig. 1(a). The $\mathrm{M}_{6}$ transistor is added to reduce the maximum drain-to-source voltage $\left(\mathrm{V}_{\mathrm{DS}}\right)$ of $\mathrm{M}_{5}$ transistor to avoid the gate-oxide overstress. However, the sampling capacitance $\mathrm{C}_{\mathrm{S}}$ in the sample-and-hold amplifier with the bootstrapped technique is usually designed with several $\mathrm{pF}$ to improve the circuit performance. The different RC delay times between the sampling network $\left(\mathrm{M}_{\mathrm{S}}\right.$ and $\left.\mathrm{C}_{\mathrm{S}}\right)$ and the bootstrapped network $\left(\mathrm{M}_{1}-\mathrm{M}_{8}\right.$ and $\left.\mathrm{C}_{\mathrm{b}}\right)$ will induce the transient gate-oxide overstress across the gate-to-drain terminals of the switch $\mathrm{M}_{\mathrm{S}}$ to cause the long-term reliability issue in the sampleand-hold amplifier with the bootstrapped technique.

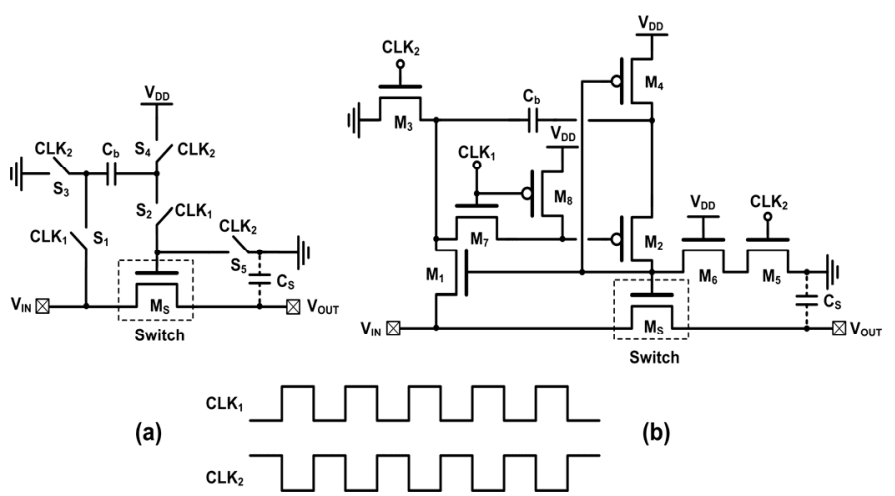

FiguRE 1. (A) CONCEPTUAL SCHEMATIC, AND (B) DETAIL CIRCUIT IMPLEMENTATION, OF BOOTSTRAPPED TECHNIQUE FOR SAMPLE-ANDHOLD AMPLIFIER (SHA).

The sample-and-hold amplifier with the bootstrapped technique has a long-term reliability problem, which causes the circuit performance degradation. The overstress voltage on the gate oxide of the switch device depends on the voltages of input and clock signals. The obvious degradation of circuit performance in the sample-andhold amplifier with bootstrapped technique needs a long-term operation, which may need many years, to measure the change under the gate-oxide degradation of switch device. In order to accelerate the degradation of circuit performance, the sample-and-hold amplifier with the gate-oxide reliability test circuit is proposed in Fig. 2. The sample-and-hold amplifier with the open-loop configuration is used to verify the gate-oxide reliability of the bootstrapped MOS switch. In Fig. 2, the operational amplifier with the folded-cascode structure is used to realize the buffer. The sampling capacitance $C_{S}$ is realized by a PMOS transistor.

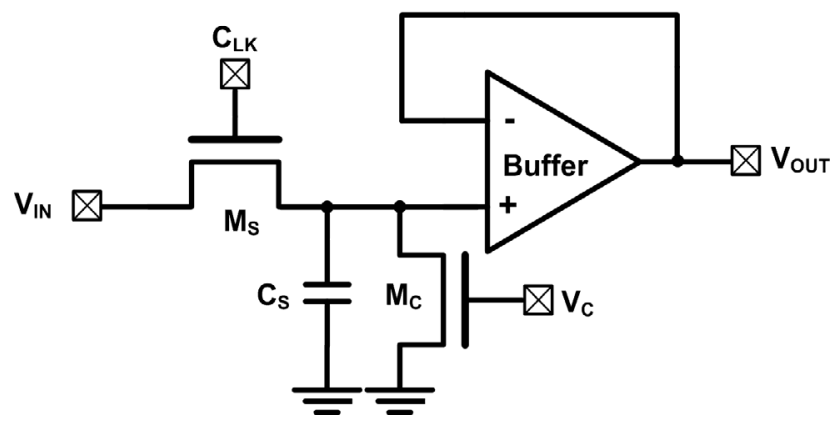

FiguRE 2. COMPLETE CIRCUIT WITH THE GATE-OXIDE RELIABILITY TEST CIRCUIT FOR SAMPLE-AND-HOLD AMPLIFIER. 
The normal operating voltage and the gate-oxide thickness $\left(\mathrm{t}_{\mathrm{ox}}\right)$ of all MOSFET devices in the sample-and-hold amplifier with the gate-oxide reliability test circuit are $1.2 \mathrm{~V}$ and $2.63 \mathrm{~nm}$, respectively, in a 130-nm CMOS process. The control device $\mathrm{M}_{\mathrm{C}}$ is used to control the drain voltage of the switch $\mathrm{M}_{\mathrm{S}}$. The device ratio of the switch $\mathrm{M}_{\mathrm{S}}$ is determined by the sampling frequency of the sample-and-hold amplifier. Therefore, the device ratio of the control device $\mathrm{M}_{\mathrm{C}}$ should be designed larger than that of the switch $\mathrm{M}_{\mathrm{S}}$. If the device ratio of the control device $\mathrm{M}_{\mathrm{C}}$ is smaller than that of the switch $\mathrm{M}_{\mathrm{S}}$, the drain voltage of control device $\mathrm{M}_{\mathrm{C}}$ will not be kept at ground. In normal operation, the control voltage $\mathrm{V}_{\mathrm{C}}$ is biased to ground, so the control device $\mathrm{M}_{\mathrm{C}}$ is turned off. The sample-and-hold amplifier can be successfully operated under the sample and hold modes, respectively. In the gate-oxide overstress test, the control voltage $\mathrm{V}_{\mathrm{C}}$ is biased to supply voltage, and the input signal $\mathrm{V}_{\mathrm{IN}}$ is kept to the supply voltage. The voltage at $C_{L K}$ node can be applied with any voltage level higher than the supply voltage to overstress the gate oxide of switch device. The voltage across the gate-to-drain terminals of the switch $M_{S}$ is controlled by the $\mathrm{C}_{\mathrm{LK}}$ voltage. This test circuit can be used to simulate the overstress across the gate-to-drain terminals of switch $\mathrm{M}_{\mathrm{S}}$ in the sample-and-hold amplifier with bootstrapped technique.

\section{OVERSTRESS TEST RESULtS}

When the sample-and-hold amplifier with the gate-oxide test circuit operates in the overstress mode, the input signal $V_{\text {IN }}$ is biased to supply voltage, and the control voltage $\mathrm{V}_{\mathrm{C}}$ is set to supply voltage. In order to observe the circuit performance degradation of the sample-and-hold amplifier due to the gate-oxide degradation of switch device, the voltage at $\mathrm{C}_{\mathrm{LK}}$ node is biased to $1.8 \mathrm{~V}$ for accelerating the gate-oxide degradation of switch device. Only the gate-to-drain terminals of the switch $\mathrm{M}_{\mathrm{S}}$ is overstressed to simulate the sample-and-hold amplifier with the bootstrapped technique. The frequency-domain waveforms are re-evaluated under this overstress condition. Figs. 3(a) and 3(b) show the frequency spectrum at $\mathrm{V}_{\text {OUT }}$ node under different stress times with the $25 \mathrm{MHz}$ square signal (sampling frequency) at $\mathrm{C}_{\mathrm{LK}}$ node and $2 \mathrm{MHz}$ sinusoidal signal at $\mathrm{V}_{\mathrm{IN}}$ node. The gate-oxide overstress on the switch $\mathrm{M}_{\mathrm{S}}$ degrades the performance of the sample-and-hold amplifier. The spurious free dynamic range (SFDR) of the sample-and-hold amplifier is degraded by the gate-oxide overstress on the switch device from $37.48 \mathrm{~dB}$ to $9.48 \mathrm{~dB}$ after the 8 -hours stress time. The effective number bits of the sample-and-hold amplifier will be reduced by gate-oxide overstress on the switch device. Because the gate-oxide degradation induces the leakage current across the drain-to-gate terminals [5], the leakage current of MOS switch causes the voltage at $\mathrm{V}_{\text {OUT }}$ on the hold mode to be degraded. If the gate oxide (gate-to-drain) of the MOS switch is fully broken down, the output waveform at $V_{\text {OUT }}$ node of sample-and-hold amplifier will become square waveform due to the large leakage current. Finally, the sample-and-hold amplifier will not be functional. Therefore, the circuit performance of the sample-and-hold amplifier with the bootstrapped technique is degraded by gate-oxide degradation of switch device after long-term operation.

\section{CONCLUSION}

The impact of gate-oxide reliability on switch device in the bootstrapped circuit has been investigated and analyzed with the sample-and-hold amplifier. The frequency-domain waveforms of the sample-and-hold amplifier after different tress times have been measured. The gate-oxide overstress across the gate-to-drain terminals of the switch device induces the leakage current to degrade the voltage at $\mathrm{V}_{\text {OUT }}$ in the hold mode. After the gate-oxide overstress, the performance of the sample-and-hold amplifier is seriously degraded by gate-oxide degradation of MOS switch. The gate-oxide reliability of MOS switch in the sample-and-hold amplifier with the bootstrapped technique has been a very important application concern for analog circuits in the nano-scale CMOS processes. The bootstrapped technique designed with thick gate-oxide MOSFET device can overcome this problem. How to design the sample-andhold circuit with only thin gate-oxide devices is still a challenge to analog circuit designers.

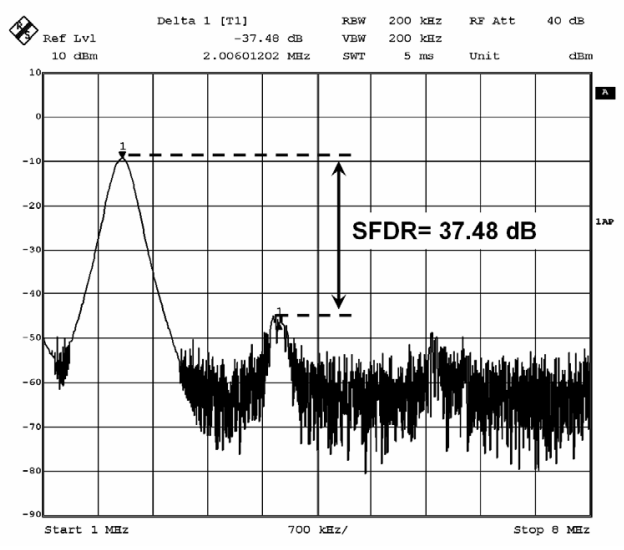

(a)

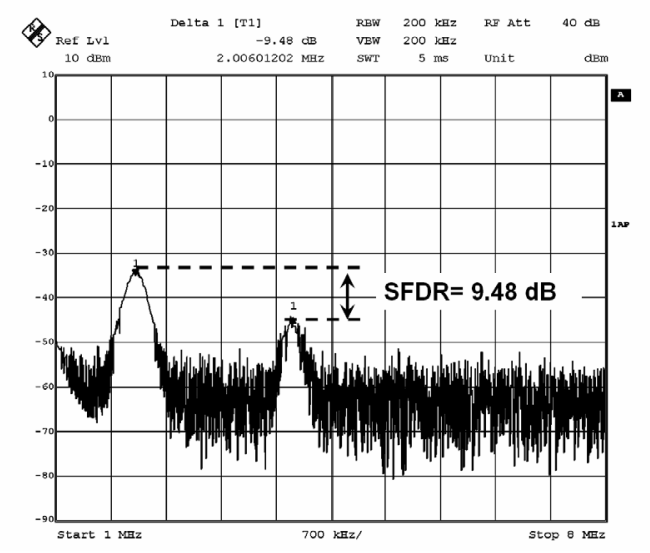

(b)

FIGURE 3. THE MEASURED FREQUENCY-DOMAIN WAVEFORMS OF THE SAMPLE-AND-HOLD AMPLIFIER WITH THE GATE-OXIDE RELIABILITY

TEST CIRCUIT UNDER DIFFERENT OVERSTRESS TIMES. (A) OVERSTRESS TIME $=0$ HOUR, AND $(B)$ OVERSTRESS TIME $=8$ HOURS.

\section{REFERENCES}

[1] A. M. Abo and P. R. Gray, "A 1.5 V, 10 bits, 14.3-MS/s CMOS pipeline analog-to-digital converter," IEEE J. Solid-State Circuits, vol. 34, pp. 599-606, May 1999.

[2] J.-B. Park, S.-M. Yoo, S.-W. Kim, Y.-J. Cho, and S.-H. Lee, “A 10-b 150-Msample/s 1.8 V 123-mW CMOS A/D converter with 400-MHz input bandwidth," IEEE J. Solid-State Circuits, vol. 39, pp. 1335-1337, Aug. 2004.

[3] S.-M. Yoo, J.-B. Park, H.-S. Yang, H.-H. Bae, K.-H. Moon, H.J. Park, S.-H. Lee, and J.-H. Kim, "A 10 b 150 MS/s 123 mW $0.18 \mu \mathrm{m}$ CMOS pipelined ADC," in IEEE Int. Solid-State Circuits Conf. Dig. Tech. Papers, 2003, pp. 326 - 497.

[4] L. Wang and S. H. K. Embabi, "Low-voltage high-speed switched-capacitor circuits without voltage bootstrapper," IEEE J. Solid-State Circuits, vol. 38, pp. 1411-1415, Aug. 2003.

[5] R. Degraeve, B. Kaczer, A. D. Keersgieter, and G. Groeseneken, "Relation between breakdown mode and breakdown location in short channel NMOSFETs and its impact on reliability specifications," in Proc. IEEE Int. Reliability Physics Symp., 2001, pp. 360-366. 